\title{
Transformational Management and Karma-Yoga Linkage
}

\author{
B. Satpathy \\ P.G Department of Business Administrations \\ Sambalpur University, Jyoti Vihar, Burla, Sambalpur, Orissa, India, 768019 \\ E-mail: bulusatpathy@indiatimes.com
}

\begin{abstract}
This study focuses on Transformational Leadership and Karma-Yoga linkage and its main objective is to test the hypothesis that the Karma-Yoga is positively related to Transformational Leadership. Transformational Leadership comprises of four factorsidealized influence, inspirational motivation, intellectual stimulation, and individualized consideration as identified by Bass (1998), the Transformational Leadership Questionnaire (TLQ) developed by MySkillsProfile.com was used to measure these factors of Transformational Leadership while the Karma-Yoga Assessment Questionnaire (KAQ) captures the four characteristics of Karma-Yoga such as significance of work, successful work, detachment from work and setting an example developed by Menon \& Krishnan (2004). Both validity and reliability of the measures of the two independent variables i.e the Transformational Leadership and the Karma-Yoga have been tested and found to be acceptable. The survey included a large private sector organization and one large public sector organization based in Eastern India. The random sample was comprised of 235 male and female managers out of which 116 responded for the survey. An examination of the results reveals that transformational leadership characteristics that emanate exclusively from personal qualities of the leader have a very strong positive relationship with Karma-Yoga. Managers practicing Karma-Yoga can very easily practice Transformational Leadership and vice-versa and they have a great promise for organizational development.
\end{abstract}

Key words: Karma-Yoga, Linkage, Transformational Leadership

\section{Introduction}

Leadership could be described as transactional when the relationship is merely about an exchange of valued things and as transformational when leaders and followers are shifted to higher levels of motivation. Besides transactional and transformational leadership, the full range of leadership behaviors also includes laissez-faire leadership wherein the leader is practically uninvolved in the relationship. Transformational leadership and laissezfaire leadership are thus at the opposite ends in terms of the degree of involvement of the leader. Burns (1978) first developed the concept of transformational leadership. Transformational leaders, through their personal traits and their relationships with followers, go beyond a simple exchange of resources and productivity. In transformational leadership, leaders address themselves to followers' wants, needs, and other motivations, as well as to their own. Transformational leadership comprises four 
factors such as idealized influence, inspirational motivation, intellectual stimulation, and individualized consideration (Bass, 1998). Idealized influence refers to leader behaviors because of which followers identify with and emulate their leaders, there is complete trust, and leaders are viewed as articulating an attainable mission and vision. Such leaders are thoroughly respected, have a very high degree of referent power, maintain high standards, and set challenging goals for their followers. Idealized influence has been operationalized and is measured through the two sub- factors of idealized influence attributed and idealized influence behavioral. Inspirational motivation involves providing emotional appeals to increase awareness and understanding of mutually desired goals. The leader elevates follower expectations. Intellectual stimulation is encouraging followers to question their old ways of doing things, or to break with the past. Followers are supported for questioning their own values, beliefs and expectations, as well as those of the leader and organization. Individualized consideration is seen when the leader treats his or her followers differently but equitably on a one-to-one basis. Not only are their needs recognized and perspectives rose, but also their means of more effectively addressing goals and challenges are dealt with.

Transformational leaders are able to recognize and address already existing but untapped needs of potential followers - needs that followers themselves may not have recognized (Burns, 1978). Very often transformational leaders motivate others to do more than they originally intended and often more than they thought possible (Bass, 1985). Transformational leaders invoke inspirational, visionary, and symbolic behaviorbehavior that is often described as charismatic (House, Spangler, and Woycke, 1991). Transformational leaders are exceptional and have extraordinary effects on their followers and eventually on their social systems. They attract strong feelings of identity from their followers, generate intense feelings about themselves, and enhance congruence in value systems between themselves and their followers (Krishnan, 2002, 2004). They possess a sense of purpose, have a mission, generate excitement at work, and heighten expectations through images and meanings (Bass, 1998). They also cultivate strong bonds and empathize with their followers.

Though many authors have considered leadership to be different than management, several others have used the two terms as synonyms or identical twins. More importantly in today's cut throat business world all managers are to be leaders, so I have followed the suit of the later group and I have coined the term transformational management style to fit into the prevailing business environment in this research paper. Transformational management style takes care of the functioning of both the managers as well as leaders. I have also used the two terms leadership and management as synonyms or identical twins in this paper.

Transformational management style is the essence of creating and sustaining competitive advantage for the managers because one of the characteristics of the transformational leadership is to have exceptional and extraordinary effects on their followers and eventually on their social systems. This can only happen if the manager is above the personal interests and leads the team towards a goal that is beneficial to both the people and the organization. This is exactly what Lord Krishna has advised to do in the 
Bhagavad-Gita while describing Karma Yoga to Arjuna. So I strongly believe that managers can effectively lead their team through the practice of Karma Yoga because the gist of Karma Yoga is Nishkama Karma that means, action conducted with a spirit of sacrifice. The Bhagavad-Gita says, "Those who are devoid of attachment, who does work as a sacrifice, such persons get liberated from the bad reactions of the actions undertaken by them" (IV.23) Again the Bhagavad-Gita has praised those who control the senses and says, "The one who controls the senses by the (trained and purified) mind and intellect, and engages the organs of action to Nishkama Karma Yoga, is a superior person than others, O Arjuna" (III.07). People practicing the philosophy of Nishkama Karma, work in the level of self-actualization as described in the hierarchy of needs professed by Maslow. Such people work for their commitment to the organization and the task entrusted to them. They are not motivated by the results that the task would beget, particularly of the personal variety. It leads to psychological satisfaction since the worker is devoid of egoism while carrying out the work. Such people naturally become the role model for others. The Bhagavad-Gita says, "Whatever noble persons do, others follow. Whatever standard they set up, the world follows" (III.21) So the team members naturally choose such managers as their leader who practices Karma Yoga. Plainly saying a person becomes a transformational leader by adopting the principles of Karma Yoga in his working.

"Societies vary in the extent to which they inculcate in their members the importance of work relative to other life roles" (Sinha, 2000: 19). The larger societal culture may socialize the members of a society such that they remain dedicated to work without bothering about what they gain from their effort. The culture of India wherein I conducted this study fundamentally differs from many other cultures in one essential aspect related to work. The people who are socialized in this culture consider themselves to be born with duties rather than with rights (Sinha, 1997). Thus, work is a duty to be discharged. I therefore operationalized Karma-Yoga through the basic belief structure of the society.

\section{Hypothesis}

According to the Bhagavad-Gita worldview, no one remains even for a moment without doing work. All are made to work under compulsion by their very nature. If a person withdraws physically from work, succumbs to inertness, and sits mentally recollecting various actions, he or she is of deluded mind and is a hypocrite (The Bhagavad-Gita Verse 5 and 6 Chapter III ). One has a duty to perform one's prescribed activities since performing actions is better than renouncing actions; by ceasing activity even bodily maintenance will not be possible (The Bhagavad-Gita Verse 8 Chapter III). The objective of human existence is to transcend nature (Prakriti) and this is best done by doing one's duty in a dedicated manner. Therefore, prescribed actions or duties should be performed without too much attachment to the personal gains of work, without interruption, and with complete dedication. It is only by performing action that a person attains the highest satisfaction. Steadfastness in action is required without much thought of the fruit (The Bhagavad-Gita Verse 45, 47, 48 Chapter II from Chakraborty, 1987; Radhakrishnan, 1977). 
Transformational leadership has been shown to have positive effects on a wide variety of work related outcomes that are affected by subordinate attitudes. These include trust in management, organizational commitment, satisfaction with leadership, work performance etc. Of particular interest is the fact that transformational leadership predicts performance even when personality characteristics are controlled statistically.

There has not yet been empirical research conducted on the effects of leadership and Karma Yoga. This type of research is critically required for two reasons. First, there are numerous studies that demonstrate a positive relationship between transformational leadership and the mediating factors identified in the work models. Karma Yoga also advocates for all these factors i.e (idealized influence, inspirational motivation, intellectual stimulation, and individualized consideration) in its essence. So it may be proposed that managers who are committed to work and their organizations selflessly practice Karma Yoga.

Karma Yoga is all about a more innovative and creative environment of working that develops the qualities of an authentic transformational leadership in managers. But I observe paucity in the research literature to prove the above hypothesis. So it is being felt necessary to carry out a survey to prove the hypothesis that Karma Yoga is the essence of developing qualities of truly transformational leadership.

Hypothesis: Karma-Yoga is positively related to Transformational Leadership.

Karma is the law of cause and effect, action and reaction. Karma Yoga is action performed with detachment, with meditative awareness. The Bhagavad-Gita states that 'action alone concerns, never its fruits; stability in success and failure, this balance is called Yoga (Chapter II, Verse 47-48). According to the Bhagavad-Gita philosophy there is a very clear concept that Karma arises due to the attractions and desires in life. We remember experiences that may have happened thirty years ago due to this Karmic link. The event that gave birth to Karma took place a long time back, but the influence of that event has carried on. Therefore, the experience of that Karma continues for an extended period until it reduces its intensity.' In philosophical terms, Karma means the primal seed of desire, which guides the destiny, thought, actions and behavior of every individual. Karma, by the nature of action, is physical or mental and originates on different planes of our being, including inherent primal seeds as well as Samskaras. Through practices, Karma can be reduced in intensity or positively transformed to achieve a balanced mind and personality.

Karma Yoga is classified as the psychological aspect to become aware of the subtle areas of one's personality, which involves the awakening of latent mental faculties and new dimensions of awareness. Actions must be performed consciously and one's attitude towards the actions should be observed. We act on the levels of speech, minds intellect, samskara and experiential realization.

In Karma Yoga it is not the actions themselves, which are considered to be important, but the frame of mind in which they are performed. The attributes of Karma Yoga are 
efficiency, equanimity, absence of expectation, ego-less-ness, renunciation of limited desires, positive thinking, and duty or dharma. These attributes fit nicely into the profile of a good manager.

\section{Method \\ Karma Vada, Karma Yoga, and Nishkama Karma}

Chakraborty (1987) puts it, "Karma Vada is an ethico-moral law of causation for regulating karma, which includes thought (Mana), statement (Vachana) and action (Karma)."Accepting Karma as inevitable, the Bhagavad-Gita says, "Surely none can remain inactive, even for a moment, everyone is helplessly driven to action by nature born qualities." (III-5). Therefore, inaction is no issue Karma is a must. "Man does not attain freedom from action without entering upon action, nor does he reach perfection merely by renunciation of action," (III-4). As you sow so you reap. Karma Vada in human affairs corresponds to the cosmic law or Ritam. As Sri Aurobindo puts it, "In the mental and moral world as in the physical world there is no chaos, fortuitous rule of chance or mere probability, but an ordered Energy at work which assures its will by law and fixed relation and steady succession and the links of ascertainable cause and effectuality."

Gandhi warned young Indians against the tendency to reject work. Work as Worship is the essence of the Karma Yoga of the Bhagavad-Gita and this is also the experience of many enlightened Rishis who were by no means superstitious. Laying emphasis upon the value of Karma Yoga, as distinguished from mere Karma the Bhagavad-Gita says, "He who, controlling the organs of sense and action by the mind and remaining unattached, undertakes the Yoga of Action (Karma Yoga) through those organs, he excels" (III-7). Rejecting inaction in favor of action, the Bhagavad-Gita says, "Therefore, do you perform your allotted duty, for action is superior to inaction" (III-8). But the final goal is Nishkama Karma. As the Bhagavad-Gita puts it, "He, whose attachment has gone, whose mind is established in knowledge and who works for the sake of sacrifice, all actions of that liberated man melt away" (IV-23).

\section{The Transformational Leadership Questionnaire (TLQ)}

The questionnaire has total of sixty-four items to measure factors of transformational leadership_idealized influence, inspirational motivation, intellectual stimulation, and individualized consideration. The TLQ assesses dimensions of leadership and management skills and style. The questionnaire reveals the extent to which one possesses transformational leadership competencies. It was designed for self-administration and takes less than 15 minutes for completion. The 64 items are divided into 4 factors: idealized influence, inspirational motivation, intellectual stimulation, and individualized consideration. A 5-point Likert scale is used to evaluate the answers. The TLQ has already been validated and has also been used by other researchers.

\section{The Karma- Yoga Assessment Questionnaire (KAQ)}

The KAQ is a questionnaire to measure the variable of Karma-Yoga and it has 10 items. It was designed for self-administration and takes less than 5 minutes for completion. The 10 items are divided into 4 factors: significance of work, successful work, detachment 
from work, and setting an example. A 4-point Likert scale is used to evaluate the answers; a higher score indicates a better understanding of the Karma-Yoga philosophy. The total score is the score of the four choices (varying 1 to 4). The KAQ has already been validated by Menon and Krishnan (2004).

\section{Validity and the Reliability of the Questionnaires}

\section{Validation}

To validate the TLQ and the Karma-Yoga in the study two different aspects of the questionnaires, namely the internal consistency and the repeatability were tested. The first aspect is related to validity, the instrument's ability to measure what it purports to measure. The internal consistency, the degree of homogeneity within a domain (set of questions for a particular factor), was determined by the degree of correlation between the answers on the questions within a domain.

The repeatability (or test-retest reliability) measures the stability of scores on the questionnaires over time. In our study repeatability was determined by comparing the scores of the first time survey with the scores of the second time survey done after 2 months taking the same respondents.

\section{Statistical analysis}

SPSS version 12 was used for data analysis. Data are presented as mean or ranges. Internal consistency was determined by calculating the Cronbach's alpha coefficients for the domains of four factors and the total score. Analysis of the test-retest reliability was done by calculating the Intraclass Correlation Coefficient (ICC) for the four factors of the TLQ, KAQ and for the total score.

\section{Internal consistency results}

The Cronbach's alpha coefficients for the domains of idealized influence, inspirational motivation, intellectual stimulation, and individualized consideration and for the total score of the TLQ questionnaire were $0.77,0.84,0.83,0.81$ and 0.93 respectively. For Karma-Yoga Questionnaire the values of Cronbach's alpha coefficients were 0.85, 0.78, 0.83, 0.76 and 0.89 for the domains of four Karma-Yoga factors: significance of work, successful work, detachment from work, setting an example and the total score respectively. A Cronbach's alpha coefficient $>0.7$ is generally accepted as good.

\section{Test-retest reliability}

The intraclass correlation coefficients (ICC) of the test-retest reliability were 0.93 and .96 for the KAQ and the TLQ total score respectively. In Table 1 the ICCs are shown for the factors and the total score.

The internal consistency of the TLQ was high for each of the domains with a Crohnbach's alpha coefficient between 0.77 and 0.93 and for KAQ it was between 0.76 and 0.89 . The two month repeatability of the TLQ in respondents was high with intraclass correlation coefficients varying between 0.86 and 0.93 and for KAQ 0.80 and 0.89 .

Therefore it can be concluded that KAQ and the TLQ are valid and reliable questionnaires to measure the perceptions of the respondents towards the Transformational Leadership, Karma-Yoga philosophy and their linkages. 
Table: 1 Repeatability

\begin{tabular}{|l|l|l|l|}
\hline Factors of TLQ & $\begin{array}{l}\text { Intraclass correlation } \\
\text { coefficient }\end{array}$ & $\mathbf{9 5 \%} \mathbf{C I}$ & p-value \\
\hline Idealized Influence & 0.93 & $0.76-0.92$ & $<0.0001$ \\
\hline $\begin{array}{l}\text { Inspirational } \\
\text { Motivation }\end{array}$ & 0.90 & $0.88-0.96$ & \\
\hline $\begin{array}{l}\text { Intellectual } \\
\text { Stimulation }\end{array}$ & 0.88 & $0.87-0.96$ & \\
\hline $\begin{array}{l}\text { Individualized } \\
\text { Consideration }\end{array}$ & 0.86 & $0.77-0.93$ & \\
\hline Total & 0.96 & $0.87-0.96$ & p-value \\
\hline $\begin{array}{l}\text { Factors of KAQ } \\
\text { Intraclass correlation }\end{array}$ & $\mathbf{9 5 \%}$ CI & $<0.0001$ \\
\hline Significance of work & 0.80 & $0.76-0.92$ & \\
\hline Successful work & 0.89 & $0.88-0.96$ & \\
\hline $\begin{array}{l}\text { Detachment from } \\
\text { work }\end{array}$ & 0.83 & $0.87-0.96$ & \\
\hline Setting an example & 0.86 & $0.77-0.93$ & \\
\hline Total & 0.93 & $0.87-0.96$ & \\
\hline
\end{tabular}

Results of the test-retest reliability analysis. The Intraclass correlation coefficients (ICC) are depicted separately for every factor and for the total questionnaire with the suitable $95 \%$ confidence interval $(95 \% \mathrm{CI})$.

\section{Survey Results and Discussion of Findings}

This study was conducted across two organizations in India. The organizations included a large private sector and one large public sector undertaking organization based in Eastern India. Leadership questionnaires were distributed to a randomly selected sample of male and female managers of these organizations. The sample size was 235 out of which 116 responded for the survey. The designations varied from chief managers (indicating a work experience of over 25 years) to project leaders (indicating possibly a work experience of 4 years).

The 116 managers answered the Transformational Leadership Questionnaire (TLQ) developed by MySkillsProfile.com. The questionnaire has total of sixty-four items to measure factors of transformational leadership-idealized influence, inspirational motivation, intellectual stimulation, and individualized consideration. The TLQ assesses dimensions of leadership and management skills and style. The questionnaire reveals the extent to which one possesses transformational leadership competencies. The managers also responded to a questionnaire for measuring the understanding of Karma-Yoga of the manager. According to the Indian worldview, there are four primary characteristics of Karma Yoga-significance of work, successful work, detachment from work, and setting an example. The ten items of the Karma Yoga assessment questionnaire (KAQ) capture these four characteristics. Managers responded to these ten items on a 4-point scale (1=Strongly disagree; 2=Disagree; 3=Neither agree nor disagree; 4=Agree / strongly agree). 
Table: 2 Self Ratings Mean Scores Using TLQ and KAQ Outcomes

\begin{tabular}{|l|c|}
\hline \multicolumn{1}{|c|}{ Leadership Characteristics (TLQ) } & Self Rating Means \\
\hline Idealized Influence & 2.8 \\
\hline Inspirational Motivation & 2.7 \\
\hline Intellectual Stimulation & 2.9 \\
\hline Individualized Consideration & 3.0 \\
\hline \multicolumn{1}{|c|}{ Karma Yoga Characteristics(KAQ) } & Self Rating Means \\
\hline Significance of Work & 2.5 \\
\hline Successful Work & 3.0 \\
\hline Detachment from Work & 2.5 \\
\hline Setting an Example & 3.0 \\
\hline
\end{tabular}

Table: 3 Correlation of Leadership Characteristics with Karma Yoga

\begin{tabular}{|l|c|c|c|c|}
\hline $\begin{array}{l}\text { Karma Yoga / } \\
\text { Transformational } \\
\text { Leadership } \\
\text { Characteristics }\end{array}$ & $\begin{array}{l}\text { Significance of } \\
\text { Work }\end{array}$ & $\begin{array}{l}\text { Successful } \\
\text { Work }\end{array}$ & $\begin{array}{l}\text { Detachment from } \\
\text { Work }\end{array}$ & $\begin{array}{l}\text { Setting an } \\
\text { Example }\end{array}$ \\
\hline Idealized Influence & +0.95 & +0.90 & +0.74 & +0.80 \\
\hline $\begin{array}{l}\text { Inspirational } \\
\text { Motivation }\end{array}$ & +0.98 & +0.74 & +0.75 & +0.76 \\
\hline $\begin{array}{l}\text { Intellectual } \\
\text { Stimulation }\end{array}$ & +0.92 & +0.75 & +0.71 & +0.71 \\
\hline $\begin{array}{l}\text { Individualized } \\
\text { Consideration }\end{array}$ & +0.97 & +0.76 & +0.73 & +0.75 \\
\hline
\end{tabular}

Pearson's R, commonly referred to as a correlation coefficient, was used to measure the relationship between Transformational Leadership characteristics and characteristics of Karma Yoga. The value of $\mathrm{R}$ ranges between -1 (a perfect negative correlation) and +1 (a perfect positive correlation). A value of 0 indicates no relationship. These relationships are summarized in Table 3. The correlation coefficients of less than .20 are being interpreted as "slight almost negligible relationships", correlations of .20 to.40 as "low correlation;" correlations of .40 to.80 as "moderate correlation;" .80 to.90 as "high correlation, marked relationship;" and correlation greater than .90 as "very high correlation, very dependable relationship."

An inspection of Table 3 reveals that transformational leadership characteristics have a consistently positive correlation with Karma Yoga in a range from .71, moderate correlation to .98 , indicative of a very strong overall relationship and it substantiates the hypothesis formulated for the study. From the Table 3 it is seen that significance of work and Inspirational Motivation is highly correlated coefficient being +.98 . The result shows 
that significance of work motivates and inspires people in work places. Significance of work is also highly related to other characteristics of transformational leadership but result shows that it is maximum related to Inspirational Motivation. Successful completion of work ideally influences people as evident from the very high value of correlation coefficient +0.90 . This suggests that success stories motivate people to venture into new enterprises. Detachment from work is moderately correlated with all characteristics of transformational leadership. This means that although it is perceived as a contributing factor for transformational leadership but it fails to show highly correlated values because sometime indifference of the leader towards the work is seen negatively by the followers and so it can be a personal feeling but cannot be exhibited publicly or else there lies the danger of being misunderstood. Setting an example in the work place is highly correlated with the Idealized Influence characteristic of transformational leadership but is moderately related with all other characteristics. This means that although it ideally influence the followers it lacks in it other vital characteristics of transformational leadership this might be because examples set by leaders are based on the individual strength of those leaders and the standard set by the leaders are sometime very high. Although it ideally influences the followers, the followers feel diffident to practice and achieve such a high standard, that is why perhaps this factor is moderately correlated with other characteristics of transformational leadership.

\section{Conclusion}

Using a relatively small sample of 116, I have utilized the Transformational Leadership Questionnaire, to make an exploratory examination to understand the transformational leadership characteristics of the managers and also through another questionnaire I have tried to understand their views towards the Karma Yoga and its impact on leadership quality. An examination of the results reveals that transformational leadership characteristics, which emanate exclusively from personal qualities of the leader, have a very strong positive relationship with Karma Yoga. Managers practicing Karma Yoga can very easily practice Transformational Leadership and vice-versa. Recalling that these results pertain to a group of only 116 managers from what is in essence a sample of convenience, preliminary conclusion of this study is that the concepts of Karma Yoga and transformational leadership are highly correlated and have great promise for organizational development.

\section{ACKNOWLEDGEMENT}

I acknowledge that the literature survey of this paper is mostly based on the work of Aparna Menon and Venkat R.Krishnan Available at: www.rkvenkat.org/aparna.pdf . I also acknowledge the works of other authors from whose works this paper draws heavily but may not have been cited properly due to oversight.

\section{References}

Bass, B. M. (1985), Leadership and performance beyond expectations, New York: Free Press.

Bass, B. M. (1998), Transformational leadership: Industrial, military, and educational impact. Mahwah, NJ: Lawrence Erlbaum Associates.

Burns, J. M. (1978). Leadership, New York: Harper \& Row. 
Chakraborty, S. K. (1987), Managerial effectiveness and quality of worklife: Indian insights, New Delhi: Tata McGraw-Hill.

Chakraborty,S.K. (Ed.), Human Response Development, New Delhi:Wiley Eastern Ltd.

House, R. J., Spangler, W. D., and Woycke, J. (1991), Personality and charisma in the US presidency: A psychological theory of leader effectiveness, Administrative Science Quarterly, 36(3), 364-396.

Krishnan, V. R. (2002), Transformational leadership and value system congruence, International Journal of Value-Based Management, 15 (1), 19-33.

Krishnan, V. R. (2004), Impact of transformational leadership on followers' influence strategies, Leadership and Organization Development Journal, 25 (1), 58-72.

Menon, A. and Krishnan,V.R. (2004), Transformational Leadership and Follower's Karma-Yoga: Role of Follower's Gender, Journal of Indian Psychology, 22 (2), pp. 50-62.

Radhakrishnan.S. (1977), The Bhagavad-Gita, New Delhi: Blackie and Sons.

Sinha, J. B. P. (2000), Patterns of work culture: Cases and strategies for culture building, New Delhi: Sage.

Sri Aurobindo. (1977), The Message of Gita, Pondicherry: Sri Aurobindo Ashram.

Swami Chinmayananda. (1992), The Holy Geeta, Mumbai: Central Chinmaya Mission Trust.

Swami Rama, (1985), Perennial Psychology of the Bhagavad Gita, Honesdale,PA,USA: The Himalayan Institute Press.

\section{Appendix I \\ Questionnaire for Measuring Karma-Yoga Characteristics \\ (Please tick the correct one as per your actual experience and do not think much to fulfill the questionnaire.)}

\section{Significance of Work}

1. I feel life is meaningless without work to do.

(1=Strongly disagree; 2=Disagree; 3=Neither agree nor disagree; 4=Agree / strongly agree).

2. I feel enthusiastic about the work that I do and uplifted by it.

(1=Strongly disagree; 2=Disagree; 3=Neither agree nor disagree; 4=Agree / strongly agree).

\section{Successful Work}

3. I feel that the most successful people are the ones who are always active in their work. (1=Strongly disagree; 2=Disagree; $3=$ Neither agree nor disagree; 4=Agree / strongly agree).

4. Mental control over the task is essential for achieving success in it.

(1=Strongly disagree; 2=Disagree; $3=$ Neither agree nor disagree; 4=Agree / strongly agree).

5. Complete dedication to one's work is required in order to succeed. 
(1=Strongly disagree; 2=Disagree; 3=Neither agree nor disagree; 4=Agree / strongly agree).

\section{Detachment from Work}

6. A certain degree of detachment to my work is essential for success in it. (1=Strongly disagree; 2=Disagree; 3=Neither agree nor disagree; 4=Agree / strongly agree).

7. An action performed without too much attachment to the result is likely to result in the highest satisfaction.

(1=Strongly disagree; 2=Disagree; 3=Neither agree nor disagree; 4=Agree / strongly agree).

8. For a job to be successful, one should relinquish ideas of self-advancement.

(1=Strongly disagree; $2=$ Disagree; $3=$ Neither agree nor disagree; 4=Agree / strongly agree).

\section{Setting an Example}

9. I like to inspire my subordinates by the force of my actions.

(1=Strongly disagree; 2=Disagree; $3=$ Neither agree nor disagree; 4=Agree / strongly agree).

10. One of the hallmarks of a good leader is that he or she can inspire his or her subordinates to behave as he or she does.

(1=Strongly disagree; 2=Disagree; $3=$ Neither agree nor disagree; 4=Agree / strongly agree). 